\title{
Cutinase structure, function and biocatalytic applications
}

\author{
Cristina M. L. Carvalho \\ Centro de Engenharia Biológica e Química \\ Instituto Superior Técnico \\ 1000 Lisboa - Portugal \\ Maria Raquel Aires-Barros \\ Centro de Engenharia Biológica e Química \\ Instituto Superior Técnico \\ 1000 Lisboa - Portugal \\ Joaquim M. S. Cabral ${ }^{1}$ \\ Centro de Engenharia Biológica e Química \\ Instituto Superior Técnico \\ 1000 Lisboa - Portugal \\ Tel: + 351.1.8419065 Fax: + 351.1.8419062 \\ E-mail: qcabral@alfa.ist.utl.pt \\ http://www.ist.utl.pt/
}

This review analyses the role of cutinases in nature and their potential biotechnological applications. The cloning and expression of a fungal cutinase from Fusarium solani $f$. pisi, in Escherichia coli and Saccharomyces cerevisiae hosts are described. The three dimensional structure of this cutinase is also analysed and its function as a lipase discussed and compared with other lipases. The biocatalytic applications of cutinase are described taking into account the preparation of different cutinase forms and the media where the different types of enzymatic reactions have been performed, namely hydrolysis, esterification, transesterification and resolution of racemic mixtures. The stability of cutinase preparations is discussed, particularly in anionic reversed micelles considering the role of hexanol as substrate, co-surfactant and stabilizer. Process development based on the operation of cutinase reactors is also reviewed.

Cutinases are hydrolytic enzymes that degrade cutin, the cuticular polymer of higher plants, which is a polyester composed of hydroxy and epoxy fatty acids (Purdy and Kolattukudy, 1975). The fatty acids of cutin are usually $n$ $\mathrm{C}_{16}$ and $n-\mathrm{C}_{18}$ and contain one to three hydroxyl groups. Ester bonds predominate in the cutins, although peroxide bridges and ether linkages have also been presented.

Cutin plays a key role in protection against the entry of pathogens into plants, and its enzymatic degradation has proved to be one of the first steps in the infection process.
Some microorganisms, including plant pathogens, have been shown to live on cutin as their sole carbon source (Purdy and Kolattukudy, 1975) and the production of extracellular cutinolytic enzymes has been presented (Purdy and Kolattukudy, 1975; Lin and Kolattukudy, 1980). Cutinases have been purified and characterized from several different sources, mainly fungi (Purdy and Kolattukudy, 1975 ; Lin and Kolattukudy, 1980; Petersen et al., 1997; Dantzig et al., 1986; Murphy et al., 1996) and pollen (Petersen et al., 1997; Sebastian et al., 1987). Evidence of a bacterial cutinase produced by a phyllospheric fluorescent Pseudomonas putida strain, cohabiting with a nitrogen-fixing bacterium Corynebacterium sp., has also been demonstrated (Sebastian et al., 1987).

The invasion of plants by phytopatogenic fungi is based on the secretion of an extracellular cutinase. It was shown that inhibitors of cutinase could prevent fungal penetration of plants and thus prevent infection (Soliday and Kolattukudy, 1983). Since this enzyme appears to play an important role in virulence, several studies have been performed to elucidate its physiological and biochemical properties (Purdy and Kolattukudy, 1975; Lin and Kolattukudy, 1980; Dantzig et al., 1986; Murphy et al., 1996; Sebastian et al., 1987; Soliday and Kolattukudy, 1983). Cutinases are serine hydrolases specific for primary alcohol esters, the dominant linkage in cutin (Murphy et al., 1996). To date, the majority of the work has been done with a fungal pathogen of peas, Fusarium solani f. pisi (Purdy and Kolattukudy, 1975; Lin and Kolattukudy, 1980; Dantzig et al., 1986; Murphy et al., 1996; Soliday and Kolattukudy, 1983). The production of cutinase seems to be highly regulated by the growth

${ }^{1}$ Corresponding author 
conditions. It is repressed by glucose and induced by hydrolyzed cutin or its major constituents, 16hydroxyhexadecanoic acid, 10,16-dihydroxyhexadecanoic acid, and 9,10,18-trihydroxypalmitic acid (Dantzig et al., 1986; Murphy et al., 1996). The hydroxyl group at the omega position is the most important factor for inducing activity (Murphy et al., 1996).

\section{Cloning and expression of cutinase}

Due to the importance of the potential applications of cutinase, this enzyme has been cloned and expressed in heterologous hosts. A Fusarium solani f. pisi cDNA library was constructed, containing the cutinase gene, and transferred to the plasmid pUC19. The cloned gene was expressed behind the signal peptide for alkaline phosphatase $(p h o A)$ in order to direct the cutinase to the Escherichia coli periplasm. The fusion of the sequences for phoA and cutinase was carried out by single oligonucleotide-directed mutagenesis using the $\mathrm{pMa} / \mathrm{c}$ type of plasmids. In the resultant $\mathrm{pMa} / \mathrm{c} 5-\mathrm{CUF}$ vector the phoA/cutinase gene fusion is under the transcriptional control of the IPTG-inducible $\mathrm{P}_{\text {tac }}$ promoter (Lauwereys et al., 1991). E. coli WK6 was used as the host for expression. High levels of cutinase have been synthesized and due to its periplasmic location the recombinant cutinase can be easily purified in large quantities (Lauwereys et al., 1991).

More recently, an efficient production system for Fusarium solani $f$. pisi cutinase in Saccharomyces cerevisiae was developed, and point mutations were introduced into the cutinase gene to optimize lipase activity (Sagt and Verrips, 1995). The original signal peptide was replaced by a yeast $\beta$-D-fructofuranosidase peptide, and the gene was cloned in a MIRY plasmid containing the $\mathrm{P}_{\text {gal }}$ promoter (Sagt and Verrips, 1995,Longhi et al., 1996). The transformant was grown in a fed-batch culture and extracellular cutinase was accumulated in the fermentation medium.

\section{Cutinase structure}

In recent years the X-ray crystal structure of several microbial (Rhizomucor miehei, Candida rugosa, Candida antartica B, Pseudomonas glumae, Chromobacterium viscosum, Rhizopus delemar, Humicola lanuginosa, Geotrichum candidum, Pseudomonas cepacia, Penicillium camembertii, and Pseudomonas mendaccino), and mammalian (human pancreatic) lipases have been reported (Longhi et al., 1997a,; Cygler and Schrag, 1997). All lipases investigated so far vary widely in size and amino acid sequence. However they belong to the class of serine esterases and to the superfamily of the $\alpha / \beta$ hydrolases in which the nucleophilic serine is located at the enter of an extremely sharp turn between a $\beta$-strand and an $\alpha$-helix (Longhi et al., 1997a). Lipases have a catalytic machinery similar to those present in serine proteases. They are characterized by the triad Ser, His, Asp (Glu) residues, and by an oxyanion binding site that stabilizes the transition state via hydrogen bonds with two main chain amide groups (Nicolas et al., 1996).

The three dimensional structure of Fusarium solani $f$. pisi cutinase cloned and expressed in E. coli was solved at $1.6 \AA$ resolution (Martinez et al., 1992) and the resolution was recently extended at $1.0 \AA$ (Longhiet al., 1997b,Jelsch et al., 1998). Cutinase is a 197-residue protein in a compact onedomain molecule $45 \times 30 \times 30 \AA^{3}$ in size. Cutinases have a molecular weight around 22,000 daltons with highly conserved stretches, which include four invariant cysteines, forming two disulfide bridges. Fusarium solani $f$. pisi cutinase has an isoelectric point of 7.8 (Petersen et al., 1997; Egmond et al., 1996).

Cutinase is also an $\alpha / \beta$ hydrolase and has a central $\beta$-sheet consisting of five parallel strands covered by two and three helices on either side of the sheet. Cutinase belongs to the class of the serine esterases. The stretch Gly-Tyr-Ser-GlnGly containing the active site Ser120, has even stronger homology with the consensus sequence Gly-(Tyr or His)Ser-X-Gly commonly present in lipases. The catalytic triad Ser120, Asp175 and His188, is accessible to the solvent and it is located at one extremity of the protein ellipsoid, and is surrounded by the loop 80-87 and by the more hydrophobic loop 180-188 (Jelsch et al., 1998). To date, around 40 X-ray structures of cutinase and its mutants and inhibitor conjugates have been solved (Longhi et al., 1996; Longhi et al., 1997a; Nicolas et al., 1996; Martinez et al., 1992; Longhiet al., 1997b;Jelsch et al., 1998; Martinez et al., 1993; Martinez et al., 1994; Prangé et al., 1998).

Lipase activity is greatly enhanced at lipid-water interfaces. They do not hydrolyze substrates under the critical micellar concentration (cmc) and display a high activity beyond it. This phenomenon of interfacial activation, is necessary for lipases to display their activity due to the existence of a hydrophobic lid (or flap) in their structures, which covers the catalytic site. The conformational change of the lid is thought to be closely related to the interfacial activation phenomenon process (Martinez et al., 1994). The rearrangement of the lid results in a large increase in the hydrophobic surface, stabilized by interaction with the interface. Also a consequence of the movement of the lid in lipases, is the formation of the oxyanion hole, during the nucleophilic attack on the sissile bond of the substrate (Martinez et al., 1994).

Cutinases differ from classical lipases, as they do not exhibit interfacial activation. The above mentioned loops 80-87 and 180-188, bearing hydrophobic amino acids (Leu81, Gly82, Ala85, Leu86, Pro87, Leu 182, Ileu183 and Val184), may constitute the interfacial binding site (Martinez et al., 1992). Despite the existence of two sidechain bridges of amino acids Leu81 and Val184, and Leu182 and Asn84, the catalytic serine of cutinase is not buried under surface loops, but is accessible to solvent and 
substrate. The absence of a flap, masking the active-site serine, as in other lipases, probably explains why cutinase is not activated by the presence of interfaces. The binding of cutinase to interfaces seems not to require a main-chain rearrangement, as in the case of lipases, but only the reorientation of few lipophilic side chains, for example Leu81 and Leu182, that play the role of a 'mini' flap. Another important feature on cutinase structure is that the oxyanion hole is preformed in cutinase instead of being induced by ligand binding and seems to be stabilized by cutinase Ser42 side chain (Nicolas et al., 1996).

\section{Cutinase function}

The definition of cutinase structure by crystallographic methods and protein engineering, has given the opportunity to clarify its mechanism of action, and to improve the understanding of cutinase structure-function relationships (Longhi et al., 1996; Jelsch et al., 1998; Martinez et al., 1993), and to widen the range of potential applications (Okkels, 1997a; Okkels, 1997b; Unilever, 1994a, b; Genencor, 1989).

A few studies aimed to elucidate whether cutinase can be considered as a member of the family of lipases or rather as an esterase (Egmond and van Bemmel, 1997). Timeresolved fluorescence was used to observe directly the formation of enzyme-lipid aggregates, leading to the conclusion that cutinase behaves like a lipase rather than an esterase. Even below the cmc of micellar substrates, kinetically relevant cutinase complexes may be formed. This also explains why cutinase, having an exposed active site serine, can behave like interfacial activated lipases.

A lipase stereo- and regioselectivity towards tri- and diacylglycerols study, using a monolayer technique, was undertaken to complement the structural data (Rogalska et al., 1997). The results obtained with prochiral triacylglycerols showed that Fusarium solani cutinase and mammalian gastric lipases display a distinct stereopreference for position sn-3, while Rhizomucor miehei and Pseudomonas sp. lipases show some preference for position $s n-1$.

Triacylglycerol analogues have been used to study the substrate specificity and selectivity of cutinase and its mutants (Egmond and van Bemmel, 1997; Rogalska et al., 1997; Mannesse et al., 1995a; Mannesse et al., 1995b; Zandonella et al., 1995; Mannesse et al., 1997). Triglyceride analogues were synthesized replacing one of the primary acyl ester functions by an alkyl group, while the secondary acyl ester bond was replaced by an acyl amino bond (Mannesse et al., 1995a). These synthetic triglycerides contain only one hydrolyzable ester bond and they are suited to study the influence of the chain length at the 1-, 2-, and 3-position on lipase activity and on stereoselectivity. It was found that cutinase is very sensitive to the length and distribution of the acyl chains, being highly specific for hydrolysis of the $s n-3$ acyl chain of triacylglycerols being the highest activities obtained for chain lengths of about five carbon atoms (Egmond and van Bemmel, 1997; Mannesse et al., 1995a). This indicates that the binding cleft of cutinase, that accommodates the chain to be split off, must be relatively short. Regarding enantioselectivity, the enzyme preferentially hydrolyzes the (R)-enantiomers (Mannesse et al., 1995a).

\section{Biocatalytic applications of cutinase}

As a lipolytic enzyme, cutinase has been presented as a versatile enzyme showing several interesting properties for applications in industrial products and processes. Hydrolytic and synthetic reactions catalyzed by cutinase have potential use in the dairy industry for the hydrolysis of milk fat, in house hold detergents, in the oleochemical industry, in the synthesis of structured triglycerides, polymers and surfactants, in the synthesis of ingredients for personal-care products, and the synthesis of pharmaceuticals and agrochemicals containing one or more chiral centers. At low water activities transesterification of fats and oils or (stereo)selective esterification of alcohols can be achieved.

Some of these processes are already applied in industry, while others are still under evaluation at a research level and are discussed in sections A and B.

In recent years, the esterasic activity of cutinase has been largely exploited and several applications in different industrial fields have been presented. Taking profit from its in vivo cutinolytic activity, an enzymatic preparation containing cutinase has been developed for increasing the pharmacological effect of agricultural chemicals (Genencor, 1988).

In vitro, cutinases display hydrolytic activity towards a broad variety of esters, from soluble synthetic esters (e.g. pnitrophenyl esters) to insoluble long-chain triglycerides. Moreover, cutinases can be considered as a link between esterases and lipases as they efficiently hydrolyze soluble esters and emulsified triacylglycerols (Egmond and van Bemmel, 1997). Therefore cutinase has been evaluated as a lipolytic enzyme in laundry and dishwashing detergent formulations (Okkels et al., 1997; Egmond and van Bemmel, 1997; Unilever, 1994a). Some benefits were achieved with cutinase, when compared with a commercial lipase, Lipolase ${ }^{\mathrm{TM}}$, on the removal of triacylglycerols in a single wash process, as cutinase was able to hydrolyze the fats in the absence of calcium (Egmond and van Bemmel, 1997).

Another interesting application of cutinase is on the degradation of plastics. Polycaprolactone, a synthetic polyester, was hydrolyzed to water-soluble products by cutinase from Fusarium solani f. pisi (Murphy et al., 1996). 


\section{A. Preparation of cutinase to be used as a biocatalyst in non-conventional media}

Cutinase has been predominantly used in non-aqueous media, although it does not present interfacial activation and acts on soluble substrates, namely natural and artificial short chain esters. The water-soluble substrates are very convenient to carry out kinetic characterization, stability and structural studies. In non-aqueous media, or nonconventional media, cutinase has performed synthetic reactions (Sjursnes et al., 1998), using hydrocarbons, hexane and isoctane, as solvents to solubilize the lipophilic substrate or using the pure substrates as the organic phase.

Cutinase has been used in different forms in the reaction media, namely as a free preparation, encapsulated in reversed micelles and immobilized on solid supports.

Lyophilized cutinase has been used to elucidate its mechanism of reaction, in stereoselectivity, specificity (Rogalska et al., 1997; Mannesse et al., 1995a; Mannesse et al., 1995b; Zandonella et al., 1995) and kinetic (Sjursnes et al., 1998) studies, including esterification (Sarazin et al., 1992; Sarazin et al., 1995; Melo et al., 1995a) and transesterification (Parvaresh et al., 1992; Lamare and Legoy, 1995; Lamare et al., 1997) reactions. Lyophilized cutinase was also added to an aqueous/triolein biphasic system to perform the hydrolysis of this triglyceride into oleic acid and glycerol (Flipsen et al., 1996).

Cutinase was immobilized onto solid supports, either adsorbed or covalent coupled, and used in different hydrolytic (Gonçalves et al., 1998a; Gonçalves et al., 1996a; Gonçalves et al., 1995), esterification (Sjursnes et al., 1998; Sereti et al., 1997), and transesterification (Parvaresh et al., 1992; Lamare and Legoy, 1995; Lamare et al., 1997; Serralha et al., 1998) reactions and for the resolution of racemic mixtures (Fontes et al., 1998). Most of the studies were performed with the cutinase adsorbed on Accurel EP 100, a macroporous polypropylene support (Sjursnes et al., 1998; Sereti et al., 1997), and Accurel PA6, a macroporous polyamide support (Serralha et al., 1998). These supports are suitable for cutinase immobilization leading to active and stable enzyme preparations.

The covalent coupling of cutinase on silica and derivatized silica supports was also evaluated (Gonçalves et al., 1998a; Gonçalves et al., 1995), however, the coupling yields (6$26 \%$ ) and thermal stability are relatively low. These results show that covalent coupling seems not to be an adequate method for cutinase immobilization.

Cutinases have been succesfully immobilized on zeolites by adsorption (Gonçalves et al., 1996; Serralha et al., 1998; Fontes et al., 1998) and used in the hydrolysis of tricaprylin (Gonçalves et al., 1996a), in the alcoholysis of butyl acetate with hexanol (Serralha et al., 1998) and in the racemic resolution of 1-phenylethanol in supercritical fluids (Fontes et al., 1998). Zeolites are crystalline silico-aluminates with a very precise microporous structure, that present some well-known general features responsible for their extensive applications in catalysis, adsorption and ion-exchange (Gonçalves et al., 1996a; Serralha et al., 1998). These properties are related to the possibility of generating and regulating the acid-base and hydrophobic-hydrophilic character, and to strong selective adsorption affinities. The properties of zeolites depend mainly on their particular structure, framework composition, cation and pore structure, and can be easily modified. The water affinity and adsorption capacity of zeolites can be manipulated over a broad range. Thus, the zeolite external crystallite surface, presenting interesting properties for enzyme adsorption, can be used as an interface between an aqueous phase, within the zeolite, and an organic medium containing the substrate(s). Cutinase was successfully adsorbed onto different zeolites (Gonçalves et al., 1996a) with high coupling yields (60-80\%) and specific activities, namely on the zeolite $\mathrm{NaY}$ (9 U/mg enzyme). The immobilized cutinase displayed a very high thermal stability (45 days at $30^{\circ} \mathrm{C}$ without activity loss), which is much higher than that reported for cutinase immobilized onto other supports (Gonçalves et al., 1995).

Encapsulation of cutinase in gel matrices, e.g. calcium alginate, seems to be an inadequate method for cutinase immobilization; because of the very high hydrophilic character of the alginate polymer, both partition and diffusion effects hinder the catalytic action of cutinase, as it occurs for other lipases acting on lipophilic substrates. The specific activity is very low, 16-fold lower than a covalent coupled cutinase preparation and 40-fold lower than cutinase adsorbed onto zeolites (Gonçalves et al., 1996a; Gonçalves et al., 1995).

Alternatively, cutinase has been microencapsulated in reversed micelles of surfactants in organic media and successfully used for hydrolysis (Melo et al., 1995b), esterification (Sebastião et al., 1993; Sebastião et al., 1992; Pinto-Sousa et al., 1994; Cunnah et al., 1996) and transesterification (Cunnah et al., 1996; Carvalho et.al 1997a; Carvalho et al., 1998a; Papadimitriou et al., 1996; Carvalho et al., 1998b). Reversed micelles are a suitable system to promote biocatalysis in organic media. The solubilization of the enzyme in the water pool of reversed micelles favors the retention of the catalytic activity, the enzyme being protected against the negative effect of the solvent on its structure. Furthermore, encapsulation in reversed micelles provides a very high interfacial area, making possible the solubilization of hydrophilic and hydrophobic substrates and often enhancing enzyme activity. Separation of products and recovery of enzyme is also possible and constitutes another research field regarding the use of micelles. One of the most important parameters for optimal enzyme activity in reversed micelles is the molar ratio of water to surfactant, often called $w_{0}$. A distinct maximum in enzymatic activity is usually found when it is measured as a function of $\mathrm{w}_{\mathrm{o}}$. The size of the reversed micelles is related to this parameter. At low $\mathrm{w}_{\mathrm{o}}$ 
values, the micelles may be too small to accommodate the enzyme molecules; at high values, the large amount of water present may interfere with the enzymatic reaction. Therefore, cutinase microencapsulated in reversed micelles shows an optimal activity at $\mathrm{w}_{\mathrm{o}} 6$ for the esterification of oleic acid with hexanol in AOT/isooctane (Sebastião et al., 1993; Sebastião et al., 1992) and at $\mathrm{w}_{\mathrm{o}}$ 7-8 for the esterification of hexanoic acid with hexanol in CTAB (Cunnah et al., 1996). Moreover, for the transesterification of butyl acetate with hexanol the optimal $\mathrm{w}_{\mathrm{o}}$ range is 5-8 (Carvalho et al., 1997a). Concerning the hydrolysis of triolein the activity still increased up to $\mathrm{w}_{\mathrm{o}} 30$ (Melo et al., 1995b).

The choice of operational conditions should not be based exclusively on these values, since the best values for stability may not be coincident with the ones for activity as it will be further discussed.

In organic media it is possible to shift the reaction equilibrium towards synthesis. By a judicious control of the water content, a hydrolytic reaction of an ester to yield an alcohol and an acid can be reversed to esterification. Also, transesterification and interesterification reactions can take place at low water activity, $a_{w}$, as the level of free water is not sufficient for hydrolysis to compete. Some reports on cutinase have shown that $\mathrm{a}_{\mathrm{w}}$ is a key parameter to achieve the target synthetic reaction (Sjursnes et al., 1998; Sarazin et al., 1995). The highest ester yields have been achieved at $\mathrm{a}_{\mathrm{w}}$ values between 0.15 and 0.70 , depending on the solvent used (Sjursnes et al., 1998; Sarazin et al., 1992).

The control of reaction conditions, as well as the substrate conversion, has been improved by the use of more accurate techniques. A good example is a nuclear magnetic resonance (NMR) method that was developed to monitor on-line lipase-catalyzed reactions in organic solvents without the need to sample the reaction medium (Sarazin et al., 1992; Sarazin et al., 1995). This technique has been applied to follow the synthesis of caprylic acid n-butyl ester catalyzed by cutinase in organic media solely composed of substrates directly in the NMR tube in the probe of the spectrometer. By using ${ }^{1} \mathrm{H} \mathrm{NMR}$, the concentrations of alcohol, ester, hydroxylic hydrogen in the organic phase and hydroxylic hydrogen in the aqueous phase were measured. As far as water is concerned, ${ }^{1} \mathrm{H}$ NMR indicated that the water produced at the beginning of the reaction was retained by the cutinase (Sarazin et al., 1992). Later during the reaction, this synthesized water formed a distinct aqueous phase.

Supercritical fluids (SCF) have also been used as reaction medium for cutinase (Sereti et al., 1997; Fontes et al., 1998), being potentially useful alternatives to conventional organic solvents. Among these fluids, supercritical $\mathrm{CO}_{2}$ offers the same advantages as organic solvents and some extra advantages as: non-toxicity, non-inflammability, availability at low cost, ease of separation from substrates and products, low viscosity and high diffusivity. The esterification of hexanoic acid with hexanol (Sereti et al., 1997) and the kinetic resolution of a racemic mixture of 1phenylethanol (Fontes et al., 1998) are two examples of reactions catalyzed by cutinase in this non-conventional medium.

Another non-conventional reaction medium is the gas/solid system, performed in the absence of solvent and liquid phase. A gas/solid reaction system has been developed for the transesterification (Parvaresh et al., 1992; Lamare and Legoy, 1995; Lamare et al., 1997) and hydrolysis (Lamare et al., 1997) reactions of short volatile alcohols and esters catalyzed by lyophilized and adsorbed cutinase. A continuous gas/solid bioreactor was set-up in which a solid phase composed of a packed enzymatic preparation was continuously percolated with carrier gas which fed substrates and removed products. The enzymatic activity was found to be highly dependent of the water activity, the optimal results for transesterification corresponding to the complete hydration coverage of the protein (Lamare and Legoy, 1995 ).

\section{B. Cutinase performance in hydrolytic and synthetic reactions}

\section{Hydrolysis}

Hydrolysis of triglycerides and analogues by cutinase have been widely studied in several reaction systems, namely in AOT reversed micelles (Melo et al., 1995b) and in a biphasic system. In the two-phase system, the conversion of triolein was followed by the use of a monolayer technique (Flipsen et al., 1996). An optimum $\mathrm{pH}$ in the range of 9-10 was found in both systems. The apparent kinetic constants for triolein (Melo et al., 1995b) were determined: $\mathrm{k}_{\text {cat }}=1630$ $\min ^{-1}, \mathrm{~K}_{\mathrm{m}}=395 \mathrm{mM}$ and $\mathrm{k}_{\mathrm{cat}} / \mathrm{K}_{\mathrm{m}}=4.1 \mathrm{~min}^{-1} \mathrm{mM}^{-1}$. The kinetic analysis of the hydrolysis of other triglycerides, tricaprylin, trilaurin and trimyristin, was also performed. Cutinase presented higher activity and specificity for the shorter chain triglyceride under study, tricaprylin, $K_{m}=132 \mathrm{mM}$ and $\mathrm{k}_{\mathrm{cat}} / \mathrm{K}_{\mathrm{m}}=8.2 \mathrm{~min}^{-1} \mathrm{mM}^{-1}$. These results are in accordance with others obtained on the selectivity and specificity of cutinase (Mannesse et al., 1995a).

Tricaprylin hydrolysis by cutinase adsorbed onto $\mathrm{NaY}$ zeolite (Gonçalves et al., 1996), covalent coupled on porous silica (Gonçalves et al., 1995) and entrapped in calcium alginate (Gonçalves et al., 1995) has also been studied. The optimum $\mathrm{pH}$ was around 8 for the three cutinase preparations. The highest specific activity was obtained for the adsorbed cutinase.

Entrapped cutinase presented a Michaelis-Menten type of kinetics for substrate concentrations below $200 \mathrm{mM}$, substrate inhibition was observed at $400 \mathrm{mM}$. The apparent kinetic constants were $\mathrm{k}_{\mathrm{cat}}=6.51 \mathrm{~min}^{-1}$ and $\mathrm{K}_{\mathrm{m}}=35.6 \mathrm{mM}$ (Gonçalves et al., 1995). The apparent specific constant $\left(\mathrm{k}_{\mathrm{cat}} / \mathrm{K}_{\mathrm{m}}\right)$ was $0.183 \mathrm{~min}^{-1} \mathrm{M}^{-1}$. For covalent binding immobilization, diffusional limitations were present at low 
substrate concentrations (up to $35 \mathrm{mM}$ ) and substrate inhibition was observed for concentrations higher than 150 $\mathrm{mM}$. With the adsorbed cutinase a $\mathrm{k}_{\text {cat }}$ value of $1.74 \mathrm{~min}^{-1}$ and an apparent $\mathrm{K}_{\mathrm{m}}$ of $186 \mathrm{mM}$ were obtained (Gonçalves et al., 1995).

\section{Esterification}

The synthesis of fatty acid esters by cutinase has been analyzed in reversed micelles of both anionic, AOT, (Sebastião et al., 1993; Sebastião et al., 1992) and cationic, CTAB, (Cunnah et al., 1996) surfactants. The oleic acid esterification with aliphatic alcohols by microencapsulated cutinase in AOT reversed micelles showed that cutinase has a preference for $\mathrm{C}_{5}$ to $\mathrm{C}_{6}$ alcohols, reflecting both the intrinsic selectivity of the enzyme and the different accessibility of the alcohol substrates to the cutinase active site (Sebastião et al., 1993; Sebastião et al., 1992). The effect of the fatty acid chain length on the esterification of hexanol was also evaluated, and the maximum activity was obtained with butyric acid, confirming the cutinase selectivity for short chain substrates. The same reactions were also performed with cutinase encapsulated in CTAB reversed micelles (Cunnah et al., 1996) and similar conclusions can be drawn; the cutinase activity was maximal for the esterification of hexanol with butyric acid. However the cutinase activity in AOT reversed micelles was higher than in CTAB reversed micelles.

The esterification of hexanol with butyric acid was also investigated by other authors (Sjursnes et al., 1998), using cutinase adsorbed on a macroporous polypropylene support in both water-immiscible (hexane and diisopropyl ether) and water-miscible (acetonitrile) solvents. This reaction was used as a model system to evaluate the reactants solvation effects on cutinase, namely solvation of reactants. The results showed that the optimum water activity decreased with increasing polarity of the solvent. Substrate solvation was found to be most strongly affected by water in acetonitrile. To relate to solvation, kinetic parameters were determined at two water activities in each solvent. A Ping-Pong model with competitive inhibition by hexanol and butyric acid was developed. The Michaelis constants for hexanol in hexane at two $\mathrm{a}_{\mathrm{w}}$ values of 0.44 and 0.69 were 299 and $231 \mathrm{mM}$, respectively (Sjursnes et al., 1998). These values are higher than the $\mathrm{K}_{\mathrm{m}}=86 \mathrm{mM}$, obtained for hexanol in the reaction catalyzed in AOT reversed micelles (Sebastião et al., 1993). This may result from higher diffusion effects present in the supported enzyme when compared with the microencapsulated cutinase.

The esterification of hexanoic acid with hexanol has also been performed in some studies (Sereti et al., 1997; Cunnah et al., 1996). In supercritical $\mathrm{CO}_{2}$ (Sereti et al., 1997), this reaction was very slow when compared with a CTAB reversed micellar system (Cunnah et al., 1996). The initial reaction rate in supercritical $\mathrm{CO}_{2}$ is considerable lower, around $1.1 \mathrm{nmol} / \mathrm{min} . \mathrm{mg}$ protein, than that in CTAB reversed micelles, $14 \mu \mathrm{mol} / \mathrm{min} . \mathrm{mg}$ protein. Also the equilibrium in the supercritical reaction medium was only reached after 5 days.

The esterification of caprylic acid with butanol was also performed with lyophilized cutinase (Sarazin et al., 1992; Sarazin et al., 1995) in a NMR tube in the probe of the spectrometer. Around $80 \%$ of esterification could be achieved after 7 hours.

The ester synthesis of butyric acid and 2-butanol was carried out by cutinase microencapsulated in nonionic surfactant, phosphotidylcholine (Pinto-Sousa et al., 1994). The enzymatic activity for the synthesis of butyl butyrate increased with increasing substrates concentrations according to a Michaelis-Menten kinetics. However, for 2butanol and butyric acid concentrations higher than 500 $\mathrm{mM}$ and $200 \mathrm{mM}$, respectively, inhibition of cutinase was observed. The apparent Michaelis constants obtained for 2butanol and butyric acid were 47.2 and $38.8 \mathrm{mM}$, respectively.

The esterification of lauric acid and pentanol with cutinase microencapsulated in AOT reversed micelles was performed as a model system to study the structural and catalytic properties of the enzyme by using EPR spectroscopy of the labeled active site (Papadimitriou et al., 1996). The effect of water content on cutinase activity was assessed, the maximum being at $\mathrm{w}_{\mathrm{o}=9} 9$. Up to $\mathrm{w}_{\mathrm{o}} 9$ there was an increase of both activity and active site mobility. As the water content of the system became higher, the mobility of the bound spin label stabilized whereas the enzymatic activity dropped considerably. Kinetic studies allowed the determination of the apparent kinetic parameters, $\mathrm{K}_{\mathrm{m}}($ pentanol $)=208 \mathrm{mM}$ and $\mathrm{K}_{\mathrm{m}}$ (lauric acid) $=60 \mathrm{mM}$.

The synthesis of oleoyl glycerides, monoolein, diolein and triolein, catalyzed by lyophilized cutinase was demonstrated (Melo et al., 1995a) using the monomolecular film technique previously used to study the kinetics of lipase hydrolysis. The water subphase was replaced by glycerol, and a film of oleic acid was initially spread on the glycerol surface. More than $50 \%$ of the oleic acid film was acylated after 7 minutes of reaction.

\section{Transesterification}

The transesterification (alcoholysis) reaction of butyl acetate with hexanol in organic media (isooctane) has been evaluated in several systems (Serralha et al., 1998; Cunnah et al., 1996; Carvalho et.al 1997a; Carvalho et al., 1998a). The effects of the reaction conditions, namely water content, temperature, buffer molarity, $\mathrm{pH}$, surfactant (AOT), hexanol and butyl acetate concentrations, on the transesterification activity of cutinase microencapsulated in AOT reversed micelles were evaluated using the factorial design methodology (Carvalho et al., 1997a). The experimental planning included $2^{(5-1)}$ and $2^{(3)}$ factorial designs expanded further to a central composite design 
(CCD). By knowing the system response to the experimental design, the effects of each factor were calculated and its interactions determined. The response surface methodology was applied to the optimization of the transesterification reaction. Cutinase optimal activities were obtained for $490 \mathrm{mM}$ hexanol, and a temperature range of $40-50^{\circ} \mathrm{C}$. The value of $\mathrm{w}_{\mathrm{o}}$ greatly influenced the activity and the optimum range was between 5-8. AOT should be used at a concentration lower than $90 \mathrm{mM}$, due to its toxic effect on the cutinase. Despite this, cutinase displayed a higher activity in AOT reversed micelles than in CTAB reversed micelles (Cunnah et al., 1996). A pH value between 7-8 and a buffer molarity of $200 \mathrm{mM}$ are adequate for the transesterification reaction. Kinetic studies were performed for this reaction and the kinetic parameters were determined (Carvalho et al., 1998a) : $\mathrm{K}_{\mathrm{m}}($ hexanol $)=214 \mathrm{mM}$ and $\mathrm{K}_{\mathrm{m}}$ (butyl acetate) $=292 \mathrm{mM}$.

The same transesterification reaction has also been evaluated with cutinase adsorbed on zeolites and other commonly used supports (polyamide, silica and alumina) (Serralha et al., 1998). The cutinase transesterification activity was measured as a function of water activity. The best results were obtained at $\mathrm{a}_{\mathrm{w}} 0.95$ with zeolite $\mathrm{A}$ with different compensating cations. The effects of zeolite framework composition and acidity were studied. The most promising results were obtained for supports with low acidity and with lower $\mathrm{Si}$ :Al ratio, which corresponds to the composition of zeolite NaY. This last observation is in accordance with the results obtained with silica and alumina.

The alcoholysis of methyl propionate with propanol at several hydration levels $\left(a_{w}=0.2\right.$ to $\left.a_{w}=0.6\right)$ was studied in a gas/solid system (Parvaresh et al., 1992; Lamare and Legoy, 1995; Lamare et al., 1997). Cutinase was found to have an unusual kinetic behaviour. A sigmoid relationship between the rate of transesterification and the activity of methyl propionate was observed, suggesting some form of cooperative activation of the enzyme by one of its substrates. The best results were obtained at $\mathrm{a}_{\mathrm{w}}=0.6$.

\section{Resolution of racemic mixtures}

The enantiomeric resolution of a racemic mixture of 1phenylethanol by cutinase adsorbed onto zeolite $\mathrm{NaY}$ was carried out in supercritical $\mathrm{CO}_{2}$ and ethylene (Fontes et al., 1998). The catalytic activity of the enzyme was strongly dependent on water activity, with a maximum at $\mathrm{a}_{\mathrm{w}}=0.5$. However it was unaffected by pressure up to 300 bar, and was higher in supercritical ethylene than in $\mathrm{CO}_{2}$. The enzyme was very selective towards one of the isomers of 1phenylethanol, with an enantiomeric excess of $100 \%$, regardless the conditions of water activity, pressure, solvent and temperature. Based on the X-ray crystal structure of cutinase, a computer model of the structures of the transition states formed by the two enantiomers was developed. The differences between these structures helped to elucidate the preference of cutinase for the (R)- enantiomer. This is in accordance with previous enantioselectivity studies (Mannesse et al., 1995a).

A summary of the studied reactions catalyzed by cutinase is presented in Table 1.

\section{Cutinase stability}

Cutinase thermal and operational stabilities have been evaluated in different enzyme preparations and reaction conditions (Parvaresh et al., 1992; Lamare and Legoy, 1995; Gonçalves et al., 1998a; Gonçalves et al., 1996a; Gonçalves et al., 1995; Sereti et al., 1997; Melo et al., 1995b; Sebastião et al., 1993; Cunnah et al., 1996; Papadimitriou et al., 1996; Carvalho et al., 1998b; Pocalyko and Tallman, 1998; Melo et al., 1998; Melo et al., 1996a; Melo et al., 1997; Papadimitriou et al., 1997; Gonçalves et al., 1998b; Carvalho et al., 1998c; Carvalho et al., 1998d; Carvalho et al., 1998e; Pinto-Sousa et al., 1996; Gonçalves et al., 1996b; Melo et al., 1996b). Most of the studies deal with cutinase microencapsulated in reversed micelles, particularly in AOT reversed micelles, due to the higher activities obtained.

The first reports on the stability of cutinase microencapsulated in AOT reversed micelles revealed that the enzyme had very short half-life times. At $\mathrm{w}_{\mathrm{o}} 10, \mathrm{pH} 9.6$ and $25^{\circ} \mathrm{C}$ the half life was determined to be 0.15 hours (Melo et al., 1995b) and only $20 \%$ of the initial activity remained after $30 \mathrm{~min}$ at $\mathrm{w}_{\mathrm{o}} 20$ (Melo et al., 1998; Melo et al., 1996a). Steady-state fluorescence spectroscopy (Melo et al., 1998,Melo et al., 1996a), near UV absorbance (Melo et al., 1997), EPR spectroscopy (Papadimitriou et al., 1997) and circular dichroism (CD) (Gonçalves et al., 1998b) studies have been performed to probe functional and structural stability of cutinase in free form (Melo et al., 1996a; Melo et al., 1997) and in reversed micelles (Melo et al., 1998; Melo et al., 1996a; Papadimitriou et al., 1997; Gonçalves et al., 1998b). Excitation spectra were used to decompose cutinase absorbance in its Trp (one) and Tyr (six) residues, which can be used as intrinsic fluorescence probes.

A fast deactivation of cutinase in AOT reversed micelles occurs due to a reversible denaturation process. Denaturation is probably caused by the interaction between the enzyme and the surfactant interface of the reversed micelle, since in aqueous solution the enzyme supports temperatures up to $85^{\circ} \mathrm{C}$ (Lauwereys et al., 1991) and in the near absence of water (lyophilized powder), the optimum temperature for transesterification was $80^{\circ} \mathrm{C}$ (Parvaresh et al., 1992). When the size of the empty reversed micelle water-pool is smaller than cutinase, e.g. $w_{0} 5$, a three-state model describes denaturation and deactivation with an intermediate conformational state existing on the path from native to denaturated cutinase. At $\mathrm{w}_{\mathrm{o}} 20$, the size of the empty micelle was larger than cutinase and the data was well described by a two state model, in which only native and denaturated cutinase were present (Melo et al., 1998). 
Stabilization strategies for this enzymatic system have been established. An important feature that has a positive influence on cutinase stabilization was the use of alcohols, namely hexanol which greatly avoids cutinase deactivation (Sebastião et al., 1993). The half-life of cutinase in AOT reversed micelles containing $250 \mathrm{mM}$ hexanol, at $\mathrm{pH} 10$, $15^{\circ} \mathrm{C}$ and $\mathrm{w}_{\mathrm{o}} 4$ was around 60 days (Sebastião et al., 1993). The way how hexanol protects microencapsulated cutinase is still a matter of discussion.

Factorial design methodology was applied to optimize both the activity and stability of cutinase in AOT reversed micelles (Carvalho et al., 1998b; Carvalho et al., 1998c; Carvalho et al., 1998d). The design matrix included five levels to study the factors: $\mathrm{pH}$, hexanol concentration, AOT and water amounts and buffer molarity. A pH value of 8-8.5 and a buffer molarity of $200 \mathrm{mM}$ were suitable for both activity and stability (Carvalho et al., 1998b).

The surface methodology applied to the results showed that cutinase incubated at $40^{\circ} \mathrm{C}$ retained a high activity level $(90 \%)$ after three days when the $\mathrm{w}_{\mathrm{o}}$ value was 2.7. The $\mathrm{w}_{\mathrm{o}}$ values in the range 5-8 led to optimal specific activities but with lower stabilities. At $\mathrm{w}_{\mathrm{o}} 2.7$ the micelles have a radius of inner cavity of $8 \AA$, while the cutinase can be represented by a sphere with $20.5 \AA$ radius. This implies that upon encapsulation, the micelles are enlarged to host the protein and cutinase in such small micelles is structurally immobilized. This leads to stabilization by adopting a rigid configuration, its secondary and tertiary structure being preserved from denaturation, usually associated to an unfolding process. Thus, cutinase microencapsulated at a small $\mathrm{w}_{\mathrm{o}}$ could be protected against the exposure of hydrophobic internal loops and to the disruption of the disulfide bridge present in its structure that strongly affects its conformation and activity (Soliday and Kolattukudy, 1983). The unfolding process causes the exposition of cutinase tryptophan which was used to control the dependence of cutinase denaturation with $\mathrm{w}_{\mathrm{o}}$ by timedependent fluorescence intensity changes (Melo et al., 1998). This confirmed that a decrease on water content promotes cutinase stabilization in AOT reversed micelles.

A hexanol concentration of $500-600 \mathrm{mM}$ was essential to prevent cutinase deactivation and at the same time allowed relatively high initial rates. Hexanol strongly influences cutinase performance in AOT reversed micelles as it plays a multiple role as a substrate, a co-surfactant and a stabilizer (Carvalho et al., 1998b). The stabilization by hexanol may either be due to interface alterations or its binding to a specific site on cutinase surface, by changing its conformation to a more favorable one. Being a cosurfactant, hexanol interposes in the micellar surface, which becomes more fluid and expanded. This could enlarge the micellar interface above certain hexanol concentrations, as opposed to the effect of high salt concentrations. Another effect is the reduction of surface tension and of interface disordering, which would facilitate cutinase microencapsulation and makes it less susceptible to anionic charged AOT groups (Carvalho et al., 1998b). The effect of hexanol on cutinase thermostability was further evaluated at $30^{\circ} \mathrm{C}, \mathrm{pH} 8$, and $\mathrm{w}_{\mathrm{o}} 2.7$ in the presence of $150 \mathrm{mM}$ AOT in isoctane. In the absence of hexanol a half-life of 2.7 hours was obtained, while in the presence of $1000 \mathrm{mM}$ hexanol the half-life was estimated to be 159 days. This highlights the role of hexanol as a stabilizer in this system (Carvalho et al., 1998e).

The effect of other alcohols, as pentanol, was also tested by performing its esterification with lauric acid. The study included the use of electron paramagnetic resonance (EPR) spectroscopy as a technique for understanding the catalytic behaviour of cutinase in relation to its active site conformation in restricted and controlled hydration levels in AOT reversed micelles and to elucidate the role of water in this enzymatic process (Papadimitriou et al., 1996). Probing the active site of cutinase with a covalently bound specific spin label, EFP-TEMPO, important information can be derived on the microenvironmental level concerning changes in conformation, microviscosity and micropolarity.

The deactivation of cutinase by anionic surfactants was recently confirmed in a study with SDS (Pocalyko and Tallman, 1998). Monomeric anionic amphipaths cause the rapid formation of a reversibly inactivated intermediate due to partial unfolding of cutinase. The partial unfolding results in a more reactive site serine toward phosphorylation but reduces reactivity with soluble alkylesters. It is likely that cationic residues mediate binding of SDS. The location of these residues is unknown; however, it has been observed that the localized reversible unfolding caused by SDS not only increases the reactivity of the active site serine but also other active site residues. Therefore it seems possible that the interaction of SDS with cutinase may be confined to cationic residues at or near the active site (Pocalyko and Tallman, 1998).

The stability of cutinase microencapsulated in cationic (CTAB) reversed micelles was also evaluated (Cunnah et al., 1996; Melo et al., 1998). Cationic reversed micelles used to encapsulate enzymes are usually formed by a cationic surfactant and a co-surfactant, often an aliphatic alcohol, which is necessary to increase the water uptake by the reversed micelle. The stability of cutinase in $\mathrm{CTAB} /$ hexanol reversed micelles is much higher than in AOT in the absence of hexanol. The enzyme displayed a half- life of over 100 days at $30^{\circ} \mathrm{C}$, using $\mathrm{pH} 8$ and $\mathrm{w}_{\mathrm{o}} 8$ with $800 \mathrm{mM}$ hexanol (Cunnah et al., 1996). It is possible that the stable nature of cutinase in CTAB reversed micelles results, not because of the less detrimental effects of this surfactant or non-association of the enzyme with the interface, but as a result of the presence of the hexanol (Cunnah et al., 1996).

The stability studies of cutinase in nonionic reversed micelles composed of phosphatidylcholine/isoctane reveal that the half life of microencapsulated cutinase is highly dependent on the water content and consequently on the 
micelle size (Pinto-Sousa et al., 1996). At $22^{\circ} \mathrm{C}$ and $\mathrm{pH}$ 10.7, the half life of cutinase was higher than 125 days at $\mathrm{w}_{\mathrm{o}} 6.5$, while at $\mathrm{w}_{\mathrm{o}} 13$ was 70 days. This surfactant seems not to influence the stability of the enzyme, this being mainly dependent on micelle size.

Stability tests of cutinase, as a lyophilized powder, were carried out in a continuous gas/solid system for the esterification of methyl propionate and propanol (Parvaresh et al., 1992; Lamare and Legoy, 1995 ). Cutinase displayed an optimum activity at $80^{\circ} \mathrm{C}$ and showed to be very thermostable: at $65^{\circ} \mathrm{C}$ no activity loss was detected after 72 hours. This result confirms that enzymes in a dehydrated form are more resistant to thermoinactivation, allowing the use of high temperatures.

The stability of cutinase immobilized on solid supports was reported (Gonçalves et al., 1998a; Gonçalves et al., 1996a; Gonçalves et al., 1995; Sereti et al., 1997; Gonçalves et al., 1996b). Immobilization of cutinase by covalent binding onto silica led to very low stability, with a half-life of 24 minutes (Gonçalves et al., 1995), as the enzyme is strongly affected by covalent coupling and is in direct contact with the solvent. When cutinase is entrapped in calcium alginate, in spite of the low initial rates, the stability is very high, no deactivation being observed after 58 days. This is probably due to the hydrophilic character of alginate, which protects the enzyme against solvent deactivation (Gonçalves et al., 1995).

In a stability storage test, cutinase immobilized onto silica derivatives, Biosil- $\mathrm{NH}_{2}$ and Biosil-Dextran- $\mathrm{NH}_{2}$, showed high retention of initial activities, $97 \%$ and $78 \%$, respectively, after 50 days at $4^{\circ} \mathrm{C}$ in a stability storage test (Gonçalves et al., 1998a; Gonçalves et al., 1996b). Differential Scanning Calorimetry (DSC) showed that the immobilized enzyme was more stable than the free cutinase, as $\mathrm{T}_{\mathrm{M}}$ for free cutinase was $119^{\circ} \mathrm{C}$, while for immobilized cutinase was $128^{\circ} \mathrm{C}$ (Gonçalves et al., 1996b).

The stability of cutinase adsorbed onto a macroporous polypropylene support, was tested in supercritical $\mathrm{CO}_{2}$ at $45^{\circ} \mathrm{C}$ and 130 bar (Sereti et al., 1997). The cutinase displayed considerable stability in this system since only $10 \%$ of the initial activity was lost after 6 days of incubation under these reaction conditions.

Cutinase adsorbed onto zeolite $\mathrm{NaY}$ in the presence of isoctane $(95 \%)$ and water $(5 \%)$

remained fully stable after 45 days at $30^{\circ} \mathrm{C}$ (Gonçalves et al., 1996a). This high stability is probably due to the high retention of water by the zeolite matrix, which provides the adequate microenvironment to the adsorbed cutinase by maintaining the required hydration level of the enzyme.

\section{Process development : cutinase bioreactors}

Very few works have been published considering process development and cutinase bioreactors (Parvaresh et al.,
1992; Carvalho et al., 1998d; Gonçalves et al., 1998c; Carvalho, 1998; Carvalho et al., 1997b; Carvalho et al., 1998f).

A continuous packed bed gas/solid bioreactor was developed to perform the transesterification of methyl propionate and propanol using lyophilized cutinase as the solid phase (Parvaresh et al., 1992). The scope of the study was limited as no data were presented showing the influence of gas flow rate on the conversion. The major feature of this study was the continuous reaction for 150 hours at $65^{\circ} \mathrm{C}$ without loss of enzymatic activity.

A batch stirred tank reactor (BSTR) performance was analyzed for tricaprylin hydrolysis with cutinase adsorbed onto zeolite NaY (Gonçalves et al., 1998c). Kinetic studies were performed in this type of reactor as well as mass transfer effects on the enzymatic activity. Mass transfer coefficient, $\mathrm{k}_{\mathrm{L}} \mathrm{a}$, was estimated based on the experimental data obtained at different agitation rates.

The most complete study was performed in a reversed micellar membrane reactor (MBR) containing microencapsulated cutinase for the transesterification of butyl acetate with hexanol (Carvalho, 1998; Carvalho et al., 1997b; Carvalho et al., 1998f). Cutinase was microencapsulated in AOT reversed micelles using the results from the stability studies optimization (Carvalho et al., 1998b; Carvalho et al., 1998c): $\mathrm{w}_{\mathrm{o}} 2.7$ and 1M hexanol. A ceramic membrane of 15,000 Da molecular weight cutoff was used (Carvalho et al., 1998d; Carvalho, 1998; Carvalho et al., 1997b; Carvalho et al., 1998f).

This membrane is constituted by a carbon support recovered by a zirconium layer, and was proved to be resistant to organic solvents and drastic $\mathrm{pH}$ conditions. Similar results were obtained for cutinase performance in the MBR operating in a total recirculation mode and in a BSTR at $1 \mathrm{M}$ hexanol with $100 \mathrm{mM}$ on $1 \mathrm{M}$ butyl acetate. The influence of the flow rate on the conversion degree was evaluated and by increasing the residence time, $80 \%$ conversion was experimentally obtained. The continuous MBR was successfully modeled assuming continuous stirred tank reactor (CSTR) behaviour. The MBR was continuously operated for five weeks maintaining a level of $60 \%$ conversion, leading to an estimated cutinase half life of 717 days, which represents a 4.5 fold increase when compared with the thermostability of microencapsulated cutinase in the presence of $1 \mathrm{M}$ hexanol (Carvalho et al., 1998e). This work shows that by medium and reactor engineering it is possible to overcome the inactivation of cutinase by the anionic surfactant, making the potential applications of cutinase relevant. A significant advance has been made improving cutinase stabilization whereas high conversion yields have been achieved. The high productivities and operational stability obtained make this reversed micellar reactor system promising for biotransformation processes. 
Table1. Reported biocatalytic applications of cutinase.

\begin{tabular}{|c|c|c|c|c|c|}
\hline & & & Substrates & Enzymatic preparation & Ref. \\
\hline \multirow{13}{*}{$\begin{array}{l}\mathbf{R} \\
\mathbf{E} \\
\mathbf{A} \\
\mathbf{C} \\
\mathbf{T} \\
\mathbf{I} \\
\mathbf{O} \\
\mathbf{N}\end{array}$} & \multirow{8}{*}{ Hydrolysis } & \multirow{5}{*}{ Triglycerides } & \multirow[t]{2}{*}{ Triolein } & $\begin{array}{l}\text { Reversed micelles of } \\
\text { AOT/isoctane }\end{array}$ & $\begin{array}{l}\text { Melo et al., } \\
1995 \mathrm{~b}\end{array}$ \\
\hline & & & & $\begin{array}{c}\text { Aqueous/triolein biphasic } \\
\text { medium }\end{array}$ & $\begin{array}{l}\text { Flipsen et } \\
\text { al., } 1996\end{array}$ \\
\hline & & & \multirow[t]{3}{*}{ Tricaprylin } & Immobilization onto zeolites & $\begin{array}{l}\text { Gonçalves } \\
\text { et al., } \\
1996 a\end{array}$ \\
\hline & & & & $\begin{array}{c}\text { Entrapment in calcium } \\
\text { alginate }\end{array}$ & $\begin{array}{l}\text { Gonçalves } \\
\text { et al., } 1995\end{array}$ \\
\hline & & & & $\begin{array}{l}\text { Covalent binding on porous } \\
\text { silica }\end{array}$ & $\begin{array}{l}\text { Gonçalves } \\
\text { et al., } \\
1995 \mathrm{c}\end{array}$ \\
\hline & & \multirow[t]{3}{*}{ Esters } & p-nitrophenyl valerate & $\begin{array}{c}\text { Micelles of SDS, Triton } \\
\text { X-100 }\end{array}$ & $\begin{array}{l}\text { Pocalyko } \\
\text { and } \\
\text { Tallman, } \\
1998 \\
\end{array}$ \\
\hline & & & $\begin{array}{l}\text { p-nitrophenyl } \\
\text { palmitate }\end{array}$ & $\begin{array}{l}\text { Immobilization on dextran and } \\
\text { derivatized silica supports }\end{array}$ & $\begin{array}{l}\text { Gonçalves } \\
\text { et al., } \\
1998 \mathrm{a}\end{array}$ \\
\hline & & & $\begin{array}{l}\text { Methyl-,ethyl-, } \\
\text { propylpropionate }\end{array}$ & Gas/solid system & $\begin{array}{l}\text { Lamare et } \\
\text { al., } 1997\end{array}$ \\
\hline & \multirow{3}{*}{ Synthesis } & \multirow{3}{*}{ Esterification } & Oleic acid+hexanol & $\begin{array}{l}\text { Reversed micelles of } \\
\text { AOT/isooctane }\end{array}$ & $\begin{array}{l}\text { Sebastião } \\
\text { et al., } \\
\text { 1993,Sebas } \\
\text { tião et al., } \\
1992\end{array}$ \\
\hline & & & Caprylic acid+butanol & Substrates in organic media & $\begin{array}{l}\text { Sarazin et } \\
\text { al., } \\
1992, \text { Saraz } \\
\text { in et al., } \\
1995\end{array}$ \\
\hline & & & Caprylic acid+butanol & Substrates in organic media & $\begin{array}{l}\text { Sarazin et } \\
\text { al., } \\
1992, \text { Saraz } \\
\text { in et al., } \\
1995\end{array}$ \\
\hline & & & Butyric acid+2-butanol & $\begin{array}{c}\text { Phosphatidylcholine/ } \\
\text { isooctane reversed micelles }\end{array}$ & $\begin{array}{l}\text { Pinto- } \\
\text { Sousa et } \\
\text { al., } 1994\end{array}$ \\
\hline & & & Oleic acid+glycerol & Organic solvents & $\begin{array}{l}\text { Melo et al., } \\
1995 \mathrm{a}\end{array}$ \\
\hline
\end{tabular}




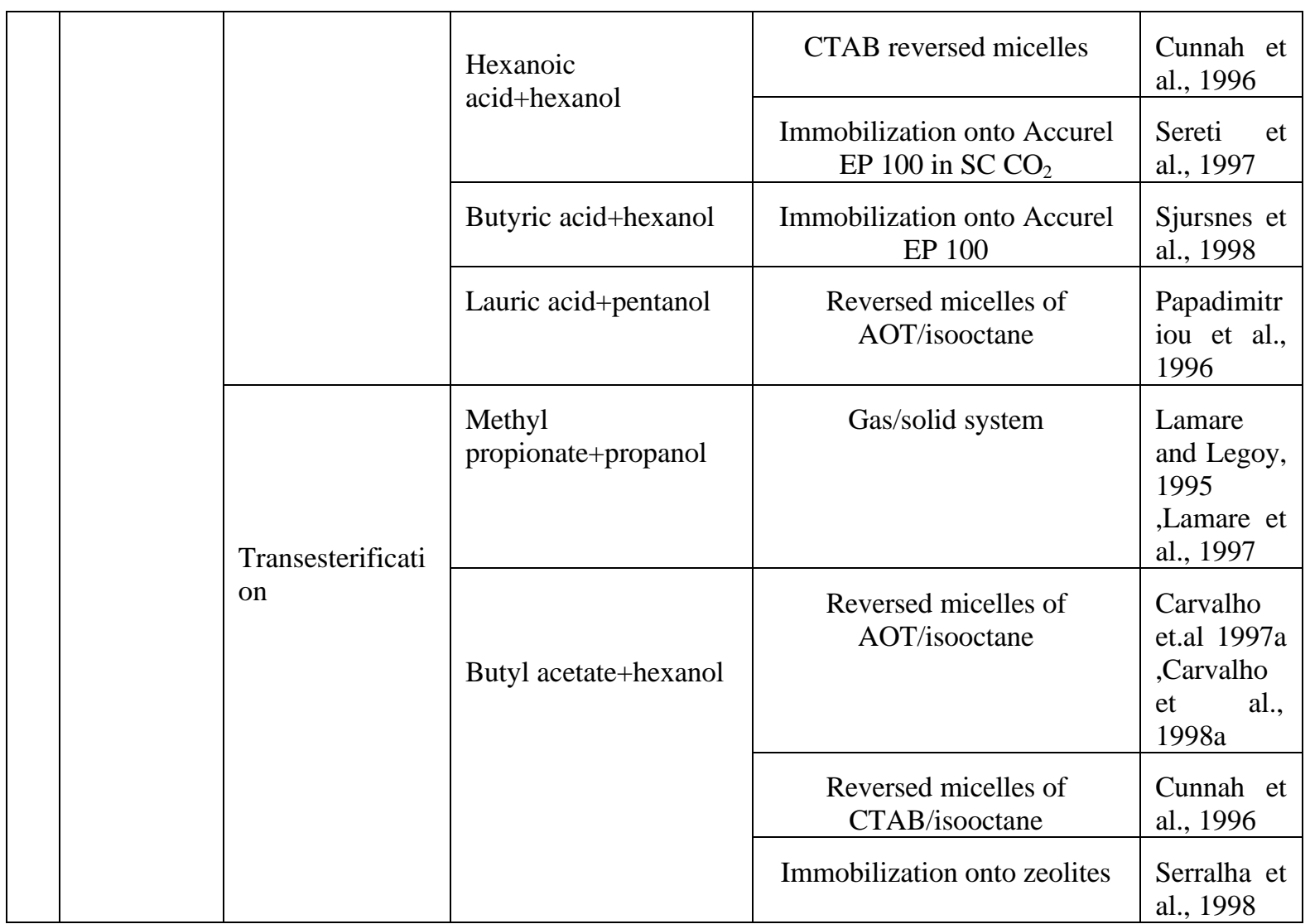

\section{References}

Carvalho C.M.L. (1998) PhD Thesis, Instituto Superior Técnico, Lisboa

Carvalho, C.M.L., Serralheiro, M.L.M., Cabral, J.M.S. and Aires-Barros, M. R. (1997a). Application of factorial design to the study of transesterification reactions using cutinase in AOT-reversed micelles. Enzyme and Microbiological Technology 21: 117-123.

Carvalho, C.M.L., Aires-Barros, M.R. and Cabral, J.M.S. (1997b) Cutinase stability in AOT reversed micelles: process development for the synthesis of short chain esters. In: Proceedings EFF'97, CBB, Rennes, pp. 191-195.

Carvalho, C.M.L., Cabral, J.M.S. and Aires-Barros, M. (1998a) Kinetics and modelling of transesterification reactions catalysed by cutinase in AOT reversed micelles. Journal of Molecular Catalalysis B- Enzymatic 5: 361-365.

Carvalho, C.M.L., Cabral, J.M.S. and Aires-Barros, M.R. (1998b) Cutinase stability in AOT reversed micelles: system optimization using the factorial design methodology. Submitted.

Carvalho, C.M.L., Serralheiro, M.L.M., Cabral, J.M.S. and Aires-Barros, M.R. (1998c) Application of factorial design to the study of cutinase stability in AOT reversed micelles: optimization of the system. In: Proceedings of III Congreso Ibérico de Biotecnologia, F.F. Polanco, P.G. Encina, G.G. Benito and M.M.P. Miranda, Universidad de Valladolid, pp. 233-236.

Carvalho, C.M.L., Aires-Barros, M.R. and Cabral, J.M.S. (1998d) Fusarium solani cutinase in reversed micelles: stabilisation strategies and operational stability. In: Enzyme Stabilisation: Methods \& Applications, T. D. Gibson, University of Leeds, p.32

Carvalho, C.M.L., Aires-Barros, M.R. and Cabral, J.M.S. (1998e) An integrated model for enzymatic reaction in reversed micellar systems: nominal and effective substrate concentrations. In: Proceedings $2^{\text {nd }}$ European Symposium on Biochemical Engineering Science, S. Feyo de Azevedo, E.C. Ferreira, K.Ch.A.M. Luyben and P. Osseweijer, University of Porto, p. 275.

Carvalho, C.M.L., Aires-Barros, M.R. and Cabral, J.M.S. (1998f) A membrane bioreactor for short chain esters synthesis. In: Proceedings $2^{\text {nd }}$ European Symposium on Biochemical Engineering Science, S. Feyo de Azevedo, E.C. Ferreira, K.Ch.A.M. Luyben and P. Osseweijer, University of Porto, p. 276. 
Cunnah, P.J., Aires-Barros, M.R. and Cabral, J.M.S. (1996). Esterification and transesterification catalysed by cutinase in reverse micelles of CTAB for the synthesis of short chain esters. Biocatalysis and Biotransformation 14:125-146.

Cygler, M. and Schrag, J.D. (1997) Structure as basis for understanding interfacial properties of lipases. In: Methods in Enzymology 284, B. Rubin and E.A. Dennis. New York, Academic Press, 1997, pp 3-85.

Dantzig, A.H., Zuckerman, S.H. and Andonov-Roland, M.M. (1986). Isolation of a Fusarium mutant reduced in cutinase activity and virulence. Journal of Bacteriology 168: 911-916.

Egmond, M.R., Vlieg, J., Verheij, H.M.,and de Haas, G.H. (1996) Strategies and design of mutations in lipases. In: Engineering of/with lipases, F.X. Malcata, Kluwer Academic Publishers, Dordrecht, 1996, 297-327.

Egmond, M.R. and van Bemmel, C.J. (1997) Impact of structural information on understanding lipolytic function. In: Methods in Enzymology 284, B. Rubin and E.A. Dennis. New York, Academic Press, 1997, pp 119-129.

Flipsen, J.A.C., Appel, A.C.M., van der Hijden, H.T.W.M. and Verrips, C.T. (1998). Mechanism of removal of immobilized triacylglycerol by lipolytic enzymes in a sequential laundry wash process. Enzyme and Microbial Technology 23:274-280.

Flipsen, J.A.C., van der Hijden, H.T.W.M., Egmond, M.R. and Verheij, H.M. (1996) Action of cutinase at the trioleinwater interface. Characterisation of interfacial effects during lipid hydrolysis using the oil-drop tensiometer as a tool to lipase kinetics. Chemistry and Physics of Lipids 84:105-115.

Fontes, N., Almeida M.C., Peres, C. Garcia, S., Grave, J., Aires-Barros, M.R., Soares, C.M., Cabral, J.M.S., Maycock, C.D. and Barreiros, S. (1998) Cutinase activity and enantioselectivity in supercritical fluids. Industrial \& Engineering Chemistry Research 37:3189-3194.

Genencor (1988). Increasing pharmacological effect of agricultural chemicals. U.S: Patent 88-08945.

Genencor (1989) Cutinase for use in detergent composition produced by culturing Pseudomonas putida. U.S. Patent 8902922.

Gonçalves, A.M., Schacht, E., Matthijs, G., Aires-Barros, M.R., Cabral, J.M.S., Gil, M.H. (1998a) Stability studies of a recombinant cutinase immobilized to dextran and derivatized silica supports. Enzyme and Microbial Technology. In press.
Gonçalves, A.M., Carvalho, C.M.L., Aires-Barros, M.R. and Cabral, J.M.S. (1998b) Structural stability of cutinase encapsulated in reversed micelles. In: Proceedings $2^{\text {nd }}$ European Symposium on Biochemical Engineering Science, S. Feyo de Azevedo, E.C. Ferreira, K.Ch.A.M. Luyben and P. Osseweijer, University of Porto, p. 274.

Gonçalves, A.M., Schacht, E., Cabral, J.M.S. and Gil, M.H. (1996b) Stability studies of a recombinant cutinase immobilised on an inorganic support. In: Proceedings of III Congreso Ibérico de Biotecnologia, F.F. Polanco, P.G. Encina, G.G. Benito and M.M. P. Miranda, Universidad de Valladolid, pp. 551-552.

Gonçalves, A.P.V., Cabral, J.M.S. and Aires-Barros, M.R. (1998c) Analysis of a BSTR reactor for triglyceride hydrolysis with an immobilised cutinase. Journal of Molecular Catalysis B- Enzymatic 5:35-38.

Gonçalves, A.P.V., Lopes, J.M., Lemos, F., Ramôa Ribeiro, F., Prazeres, D.M.F., Cabral, J.M.S. and Aires-Barros, M.R. (1996a) Zeolites as supports for enzymatic hydrolysis reactions. Comparative study of several zeolites. . Journal of Molecular Catalysis B- Enzymatic 1:53-60.

Gonçalves, A.P.V., Cabral, J.M.S. and Aires-Barros, M.R. (1995) Immobilization of a recombinant cutinase by entrapment and by covalent binding. Applied Biochemistry and Biotechnology 60:217-228.

Jelsch, C., Longhi, S. and Cambillau, C. (1998) Packing forces in nine crystal forms of cutinase. Proteins: Structure, Function, and Genetics 31:320-333.

Lamare, S. and Legoy, M.D. (1995) Working at controlled water activity in a continuous process: the gas/solid system as a solution. Biotechnology and Bioengineering 45:387397.

Lamare, S., Lortie, R. and Legoy, M.D. (1997) Kinetic studies of Fusarium solani pisi cutinase used in a gas/solid system: transesterification and hydrolysis reactions. Biotechnology and Bioengineering 56:1-7.

Lauwereys, M., De Geus, P., De Meutter, J., Stanssens, P. and Mathyssens, G. (1991) Cloning, expression and characterization of cutinase, a fungal lipolytic enzyme. In Lipases-Structure, function and genetic engineering, L. Alberghina, R.D. Schmid and R. Verger, VCH Weinheim, 1991, pp 243-251.

Lin, T. S. and Kolattukudy, P.E. (1980). Structural studies on cutinase, a glycoprotein containing novel amino acids and glucuronic acid amide at the $\mathrm{N}$ terminus. European Journal of Biochemistry 106:341351 . 
Longhi, S., Nicolas, A., Creveld, L., Egmond, M., Verrips, C.T., Vlieg, J., Martinez, C. and Cambillau, C. (1996). Dynamics of Fusarium solani cutinase investigated through structural comparison among different crystal forms of its variants. Proteins: Structure, Function, and Genetics 26:442-458.

Longhi, S., Mannesse, M., Verheij, H.M., Haas, G.H., Egmond, M., Knoops-Mouthuy, E. and Cambillau, C. (1997a) Crystal structure of cutinase covalently inhibited by a triglyceride analogue. Protein Science 6:275-286.

Longhi, S., Czjzek, M., Lamizin, V., Nicolas, A. and Cambillau, C. (1997b) Atomic resolution (1.0 ̊) crystal structure of Fusarium solani cutinase: stereochemical analysis. Journal of Molecular Biology 268:779-799.

Mannesse, M.L.M., Cox, R.C., Koops, B.C., Verheij, H.M., Haas, G.H., Egmond, M.R., van der Hijden, H. T.W.M. and Vlieg, J. (1995a) Cutinase from Fusarium solani pisi hydrolyzing triglyceride analogues. Effect of acyl chain length and position in the substrate molecule on activity and enantioselectivity. Biochemistry 34:6400-6407.

Mannesse, M.L.M., Boots, J.W.P., Dijkman, R., Slotboom, A.J., van der Hijden, H.T.W.M., Egmond, M.R., Verheij, H.M. and Haas, G.H. (1995b) Phosphonate analogues of triacyglycerols are potent inhibitors of lipase. Biochimica et Biophysica Acta 1259:56-64.

Mannesse, M.L.M., Haas, G.H., van der Hijden, H.T.W.M., Egmond, M.R. and Verheij, H.M. (1997) Chiral preference of cutinase in the reaction with phosphonate inhibitors. Biochemical Society Transactions 25:165-170.

Martinez, C., Geus, P., Lauwereys, M., Matthyssens, G. and Cambillau, C. (1992) Fusarium solani cutinase is a lipolytic enzyme with a catalytic serine accessible to solvent. Nature 356:615-618.

Martinez, C., Geus, P., Stanssens, P., Lauwereys, M. and Cambillau, C. (1993) Engineering cysteine mutants to obtain crystallographic phases with a cutinase from Fusarium solani pisi. Protein Engineering 6:157-165.

Martinez, C., Nicolas, A., van Tilbeurgh, H., Egloff, M.P., Cudrey, C., Verger, R. and Cambillau, C. (1994) Cutinase, a lipolytic enzyme with a preformed oxyanion hole. Biochemistry 33:83-89.

Melo, E.P., Ivanova, M.G., Aires-Barros, M.R., Cabral. J.M.S. and Verger, R. (1995a) Glyceride synthesis catalyzed by cutinase using the monomolecular film technique. Biochemistry 34:1615-1621.

Melo, E.P., Aires-Barros, M.R., Cabral, and J.M.S. (1995b) Triglyceride hydrolysis and stability of a recombinant cutinase from Fusarium solani in AOT-iso-octane reversed micelles. Appl. Biochem. Biotechnol. 50:45-56.

Melo, E.P., Carvalho, C.M.L., Aires-Barros, M.R., Costa, S.M.B. and Cabral, J.M.S. (1998) Deactivation and conformational changes of cutinase in reverse micelles. Biotechnology and Bioengineering 58:380-386.

Melo, E.P., Costa, S.M.B. and Cabral, J.M.S. (1996a) Denaturation of a recombinant cutinase from Fusarium solani in AOT-iso-octane reverse micelles: a steady-state fluorescence study. Photochemistry and Photobiology 63:169-175.

Melo, E.P., Aires-Barros, M.R., Costa, S.M.B. and Cabral, J.M.S. (1997) Thermal unfolding of proteins at high $\mathrm{pH}$ range studied by UV absorbance. Journal of Biochemical and Biophysical Methods 34:45-59.

Melo, E.P., Gonçalves, A.P., Sebastião, M.J., Cunnah, P.J., Carvalho, C.M.L., Lopes, J.M.M., Lemos, F., Aires-Barros, M.R. and Cabral, J.M.S. (1996b) Kinetics and stability of cutinase immobilized in reversed micelles and zeolites. In: Engineering of/with lipases, F.X. Malcata, Kluwer Academic Publishers, Dordrecht, 1996, 297-327.

Murphy, C.A., Cameron, J.A., Huang, S.J. and Vinopal, R.T. (1996). Fusarium polycaprolactone depolymerase is cutinase. Applied and Environmental Microbiology 62:456460.

Nicolas, A., Egmond, M., Verrips, C.T., Vlieg, J., Longhi, S., Cambillau, C. and Martinez, C. (1996) Contribution of cutinase serine 42 side chain to the stabilization of the oxyanion transition state. Biochemistry 35:398-410.

Okkels, J.S. (1997a) Preparing polypeptide variants with improved functional properties. U.S. Patent 97-09664.

Okkels, J.S. (1997b) Preparing polypeptide variants with improved functional properties. U.S. Patent 97-05736.

Okkels, J.S., Svendsen, A., Borch, K., Thellersen, M., Patkar, S.A., Petersen, D.A., Royer, J.C. and Kretzschmar, T. (1997). New lipolytic enzyme with high capacity to remove lard in one wash cycle. U.S. Patent 97-05735.

Papadimitriou, V., Xenakis, A., Cazianis, C.T., Stamatis, H., Egmond, M. and Kolisis, F.N. (1996) EPR studies of cutinase in microemulsions Annals NewYork Academy of Sciences 799:275-280.

Papadimitriou, V., Xenakis, A., Cazianis, C.T. and Kolisis, F.N. (1997) Structural and catalytic aspects of cutinase in w/o microemulsions. Colloid and Polymer Science 275:609-616. 
Parvaresh, F., Robert, H., Thomas, D. and Legoy, M.D. (1992) Gas phase transesterification reactions catalyzed by lipolytic enzymes. Biotechnology and. Bioengineering 39: 467-473.

Petersen, M.T.N., Martel, P., Petersen, E.I., Drabløs, F. and Petersen, S.B. (1997). Surface and electrostatics of cutinases. In:Methods in Enzymology 284, B. Rubin and E.A. Dennis. New York, Academic Press, 1997, pp 130154.

Pinto-Sousa, A.M., Cabral, J.M.S. and Aires-Barros, M.R. (1994) Ester synthesis by a recombinant cutinase in reversed micelles of a natural phospholipid. Biocatalysis 9: 169-179.

Pinto-Sousa, A.M., Cabral, J.M.S. and Aires-Barros, M. R. (1996) Stability of a Fusarium solani pisi recombinant cutinase in phosphatidylcholine reversed micelles. Biotechnology Letters 18:583-586.

Pocalyko, D.J. and Tallman, M. (1998) Effects of amphipaths on the activity and stability of Fusarium solani pisi cutinase. Enzyme and Microbial Technology 22: 647651.

Prangé, T., Schiltz, M., Pernot, 1., Colloc'h, N., Longhi, S., Bourguet, W. and Fourme, R. (1998) Exploring hydrophobic sites in proteins with xenon or krypton. Proteins: Structure, Function, and Genetics 30:61-73.

Purdy, R. E. and Kolattukudy, P.E. (1975). Hydrolysis of plant cutin by plant pathogens. Purification, amino acids composition, and molecular weight of two isoenzymes of cutinase and a nonspecific esterase from Fusarium solani f. pisi. Biochemistry 14:2824-2831.

Rogalska, E., Nury, S., Douchet, I. and Verger, R. (1997) Lipase stereo- and regio-selectivity towards tri-and diacylglycerols. Biochemical Society Transactions 25: 161164.

Sagt, C.M.J. and Verrips, C.T. (1995) Secretion of wildtype and mutant cutinases by Saccharomyces cerevisiae. Yeast 11, Special Issue, p.594.

Sarazin, C., Goethals, G., Séguin, J.P., Legoy, M.D. and Barbotin, J.N. (1992) Usefulness of NMR methods for assaying cutinase catalysed synthesis of ester in organic media. In: Biocatalysis in Non-Conventional Media, J. Tramper, M.H. Vermue, H.H. Beeftink and U. von Stockar. Elsevier Science Publishers B.V., 1992, pp. 23-29.

Sarazin, C., Ergan, F., Séguin, J.P., Goethals, G., Legoy M.D. and Barbotin J.N. (1995) NMR on-line monitoring of esterification catalyzed by cutinase. Biotechnology and Bioengineering 51:636-644.

Sebastian, J., Chandra, A.K. and Kolattukudy, P.E. (1987). Discovery of a cutinase-producing Pseudomonas sp. Cohabiting with an apparently nitrogen-fixing Corynebacterium sp. in phyllosphere. Journal of Bacteriology 169:131-136.

Sebastião, M. J., Cabral, J.M.S., and Aires-Barros, M.R. (1993) Synthesis of fatty acid esters by a recombinant cutinase in reversed micelles. Biotechnology and Bioengineering 42:326-332.

Sebastião, M. J., Cabral, J.M.S., and Aires-Barros, M.R. (1992) Synthesis of fatty acid esters by a recombinant cutinase in reversed micelles. In: Biocatalysis in NonConventional Media, J. Tramper, M.H. Vermue, H.H. Beeftink and U. von Stockar. Elsevier Science Publishers B.V., 1992, pp. 719-724.

Sereti, V., Stamatis, H. and Kolisis, F.N. (1997) Improved stability and reactivity of Fusarium solani cutinase in supercritical $\mathrm{CO}_{2}$. Biotechnology Techniques 11:661-665.

Serralha, F.N., Lopes, J.M., Lemos, F., Prazeres, D.M.F., Aires-Barros, M.R. Cabral, J.M.S., and Ribeiro, F. R. (1998) Zeolites as supports for an enzymatic alcoholysis reaction . Journal of Molecular Catalysis B- Enzymatic 4:303-311.

Sjursnes, B., Valente, C. and Halling, P. (1998) Interactions between water and medium effects on enzymes in organic media: kinetics of cutinase catalysed esterification with mutual solvation of reactants. Biotechnology and Bioengineering In press.

Soliday, C.L. and Kolattukudy, P.E. (1983). Primary structure of the active site region of fungal cutinase, an enzyme involved in phytopathogenesis. Biochemical and Biophysical Research Communication 114:1017-1022.

Unilever (1994a). Enzyme-containing surfactant compositions. U.S. Patent 94-04771.

Unilever (1994b) Eukaryotic cutinase variant with increased lipolytic activity. U.S. Patent 94-11303.

Zandonella, G., Haalck, L., Spener, F., Faber, K., Paltauf, F. and Hermetter, A. (1995) Inversion of lipase stereospecificity for fluorogenic alkyldiacyl glycerols effect of substrate solubilization. European Journal of Biochemistry 231:50-55. 